\title{
SOME OBSERVATIONS OF SAND DUNE FORMATIONS IN THE I VALLEY GOVERNORATE (EGYPT) AND EVALUATION OF CURR METHODS OF STABILIZATION
}

Mahmoud A. Hassan

\begin{abstract}
In the open desert in the surroundings of El-kharga city, capital of the new valley governorate of Egypt, a: phenomenon has been occurring over the years, that is the formation of sand dunes of various shapes. Th of these dunes by the effect of the wind, especially in winter and spring seasons is obviously jeopardous tc installations (roads, buildings, airport runways ...etc) in addition to damage of cultivated land (desertificati in real danger to national development plans. In dry zones such as the new valley desert, the scarcity of $w$ difficult to rely on traditional methods of vegetation for sand dunes fixation. Other tradituional techniques use of mulching, stones, bricks, and bitumen spraying may be non-durable and non-economocal, especiall having the deal with vast deserts with large number of dunes.

This paper presents and evaluates a field-based study of the situation of sand formations and dunes in the encompassing El-kharga city. The main objective is to examine technical durability and economic effectivel methods presently used to fight this phenomenon and to suggest alternative less costly, yet durable and e techniques. These alternative techniques are still to be subjected to in-door evaluation prior to field applici evaluation.
\end{abstract}

